\title{
Engenharia da Complexidade em Edgar Morin ${ }^{1}$
}

\author{
José RoBERTo CASTILHO PIQUEIRA ${ }^{I}$
}

\section{Introdução}

0

EMPRE que ouço um pesquisador da área de Humanas fico admirando a facilidade com que relaciona fatos históricos e linhas de pensamento filosófico com o cotidiano, além da competência linguística e intertextualidade.

Imediatamente, fico motivado a ler sobre os pontos apresentados, procuro os textos correspondentes e, em geral, fico frustrado com minha incapacidade para o bom entendimento das leituras, difíceis para quem não domina os pré-requisitos adequados.

Desta vez resolvi bancar o teimoso e não desistir com facilidade. Já que estou participando da empreitada de estabelecer a Engenharia da Complexidade no âmbito brasileiro, concluí pela obrigatoriedade do entendimento de uma das obras de Edgar Morin (2005).

$\mathrm{Li}$, reli o texto integral; e parei para pensar em alguns trechos, tentando relacioná-los com meu trabalho. Concluí que, como não sou filósofo e nem cientista, talvez fosse interessante tentar transpor as ideias apresentadas para algumas situações práticas da nova engenharia que, nos dias de hoje, emerge da riqueza da informação e da multidisciplinaridade disponível.

Assim, este manuscrito não trata de questões filosóficas ou de suas relações com o saber científico, tarefas já cumpridas com competência no original de Morin, mas do relacionamento dos princípios do pensamento complexo com a prática da engenharia, quer seja no trabalho de concepção ou de operação.

Inicio com uma discussão sobre a interpretação do significado usual do termo complexidade no âmbito da engenharia, apresentando exemplos de situações problema em que uma visão não compartimentada do projeto se faz necessária. Prossigo com a conceituação de sistema aberto, conjecturando sobre como a auto-organização emerge em um trabalho de construção de um sistema.

Nesse contexto, trato da questão da aleatoriedade de maneira ampla, incluindo-a na concepção de metassistema e na análise e síntese de processos dinâmicos, distinguindo os rápidos, relacionados com variáveis de estado, dos lentos, relacionados a variações de parâmetros constitutivos.

Da ideia de metassistema passo, fazendo uso da incompletude de Gödel, à conceituação das disciplinas envolvidas, compatibilizando unidade com diversidade e continuidade com ruptura. 
Encerro com pequenas observações no sentido de motivar a atitude do pensamento complexo, transformando as ações de engenharia em processos transdisciplinares que harmonizem os diversos modos de pensar e projetar.

\section{Engenharia e pensamento complexo}

Para conceituar complexidade no contexto da atividade de engenharia é necessário enfrentar o significado conotativo atribuído à palavra, ao longo dos anos. No dia a dia do engenheiro, complexo é tudo que apresenta dificuldades especiais em relação à concepção, projeto, montagem e operação.

Por exemplo, uma ponte ou uma via elevada é uma obra que pode ser de alta dificuldade. Sua concepção se inicia com necessidade de ligar dois locais separados por algum fator geográfico que impede ou dificulta o trânsito de pessoas e veículos.

Nessa fase estão presentes fatores econômicos, sociais, ambientais e financeiros que determinam a localização e o custo máximo permitido que, uma vez definidos, dão a partida para as primeiras especificações da obra.

Possíveis esforços naturais a serem suportados, cargas permissíveis devidas ao tráfego e fatores geométricos dão início aos cálculos. Esforços solicitantes e possíveis variações atmosféricas proporcionam a definição dos materiais, vigas, pilares, pavimentação e sustentação.

Em seguida vem o projeto executivo. Todos os materiais e custos de mão de obra são detalhados para que a obra possa ser iniciada e comece a sair do mundo do papel. A construção é árdua e requer acompanhamento constante para sanar problemas não previstos no projeto e que são inevitáveis durante o trabalho de implementação.

Pronta e inaugurada, a ponte ou via elevada precisa ser mantida, com medições constantes usando sensores de posição e de cargas. $\mathrm{O}$ resultado dessa monitoração permite a prevenção e correção de falhas.

Recorrendo ao sentido habitual da palavra, todos concordarão que conceber, projetar, construir e manter uma ponte constitui um complexo problema de engenharia.

Outro possível exemplo é o da concepção, projeto, construção e operação de uma avenida ligando dois bairros de uma cidade, com o intuito de melhorar a mobilidade urbana.

Definir o traçado da via é o ponto de partida, problema que pode envolver complicadas questões econômicas, sociais e ambientais. Não basta o conhecimento geométrico para essa tarefa: o planejamento urbano, combinando tráfego de veículos e pessoas, aliado ao atendimento das populações a serem deslocadas, são elementos essenciais nessa tarefa.

Definido o traçado, há o projeto que envolve alterações de uso do solo, com demolições, procedimentos de terraplenagem, definições de pisos e bordas e o projeto executivo, prevendo o preparo dos materiais e máquinas, bem como os custos de mão de obra. 
Do papel para a realidade, tarefa difícil, com trabalho durante possíveis intempéries, com alterações de circulação de veículos e pessoas no entorno dos canteiros de obra.

Depois das inaugurações, discursos e cortes de fitas, há a operação e manutenção, com medições que podem ser sofisticadas e ações que podem influenciar a rotina diária de motoristas e usuários de transporte individual e coletivo.

Mais uma vez, usando a linguagem diária, conceber, projetar, construir e manter uma avenida é tarefa de complexidade considerável.

Essa ideia de complexidade, explorada nos dois exemplos, carrega a carga semântica da disjunção, isto é, o problema complexo da implantação de uma ponte ou via elevada é visto como decomposto em sequência de operações, realizadas por pessoas diferentes que executam tarefas aparentemente estanques e sem conexão.

A ponte ou via elevada é vista e estudada como sistemas fechados. Suas interações com o entorno são compreendidas de uma maneira probabilista, como se fossem responsáveis pelo imponderável, atribuindo-se a elas fatores de segurança que, nem sempre, funcionam adequadamente.

A queda do elevado Paulo de Frontin (Rio de Janeiro) e o incêndio sob a ponte da Avenida Santo Amaro (São Paulo) são exemplos ilustrativos dessa falha de abordagem.

Da mesma maneira, a construção da avenida, da qual a ponte ou via elevada podem fazer parte, se for vista como sistema fechado pode trazer mais prejuízos do que benefícios. Basta olhar o "Minhocão" de São Paulo para entender o estrago urbano causado por uma melhoria de tráfego.

O pensamento complexo aparece em um contexto complementar ao da prática atual da engenharia, cujos sucessos poderiam ser enumerados em todas as áreas da atividade humana. Trata-se de adicionar aos trabalhos três novos pontos de vista: as obras como sistemas abertos, a emergência de fenômenos resultantes das não linearidades e o olhar gödeliano da incompletude.

Assim, passamos a entender a Engenharia da Complexidade como aquela que adiciona à visão tradicional da disjunção e do fechamento dos sistemas uma abordagem aberta, não linear e com a incompletude em sua gênese. Apoia-se nas conquistas e nos conhecimentos bem estabelecidos, mas proporciona uma abordagem global e transdisciplinar, trabalhando a noção de sistema de sistemas (Bertalanffy, 1968).

\section{Projetando e construindo sistemas abertos}

Nos exemplos apresentados anteriormente, fica claro o estabelecimento, a partir da fase de projeto, de sistemas que consideram sua interação com o ambiente como estática, refletida nos parâmetros físicos e coeficientes de segurança estabelecidos de início.

Essa é uma metodologia que, ao longo da história, tem sido aplicada com sucesso, mas que trabalha como se o sistema em estudo ou construção seja con- 
siderado fechado, limitando as possíveis aleatoriedades às margens de variação de parâmetros.

As possibilidades proporcionadas pelo desenvolvimento da computação, permitindo a manipulação rápida e precisa de grande quantidade de dados coloca nas mãos da engenharia poderosas ferramentas de análise e síntese de sistemas em níveis de detalhe antes não imagináveis.

Além disso, ferramentas e programas de simulação altamente eficientes permitem trabalhar as mais variadas possibilidades de montagem e execução com rapidez e alto grau de previsibilidade.

Isso nos aproxima do trabalho de concepção, projeto, execução e manutenção para um sistema aberto e sujeito às leis da Termodinâmica (Kondepudi; Prigogine, 2015), incluindo os efeitos dos processos dinâmicos de diferentes escalas temporais (Piqueira, 2009).

No exemplo da ponte ou via elevada, o novo tratamento a ser dado parte do princípio de que o sistema a ser concebido deixa de ser a ponte ou via elevada real, mas um novo elemento em que a realidade reside no elo entre o sistema e o meio ambiente, com a maior parte das interações podendo ser simuladas, permitindo decisões que levam em conta as incertezas como componentes do conjunto. Como a ponte ou via elevada está posicionada no contexto global da via da qual faz parte? Como as intempéries podem mudar sua construção e operacionalidade? Como a operação da ponte afetará a mobilidade urbana? Como o tráfego em volta afetará seus parâmetros físicos? Como a emissão de poluentes dos veículos afetará a saúde das populações vizinhas? Como a área em volta se organizará?

Enfim, há uma infinidade de perguntas e cenários a serem simulados e analisados, trazendo melhor segurança decisória e acrescentando conhecimento à Engenharia. Além disso, o processamento dos dados, medidos continuamente pelos diversos tipos de sensores durante a construção e operação, permitirá cuidados preventivos e corretivos de ampla eficiência.

Da ponte para a indústria química. A implantação da indústria de certo produto começa por uma criteriosa análise de sua adequação de benefícios e prejuízos para a população e para o meio ambiente.

Segue-se a escolha do local, problema a ser resolvido a partir de importantes questões ambientais, econômicas, sociais e de segurança. O projeto envolverá a infraetrutura a ser construída para acolher a planta, adequando-a a condições de pressão, umidade, temperatura e circulação de ar e água.

Esse é um projeto fortemente dependente do processo a ser implantado, também de alta complicação e passível de grande cuidado de produção, considerando o trabalhador interno e os cuidados ergonômicos e de segurança que protejam a vida e proporcionem dignidade.

Com a fábrica em operação, para onde irão os rejeitos? As normas de sustentabilidade serão respeitadas? A qualidade do ar e dos mananciais serão preservadas? Todos esses fatores considerados proporcionarão viabilidade econômica? 
Mais uma vez, cenários diversos poderão ser simulados e estudados cuidadosamente, modelando o físico-químico, o biológico e o antropológico, levando o transdisciplinar ao nível de interação efetiva, aproximando possíveis aleatoriedades do modelo do processo.

Assim, a Engenharia da Complexidade apresenta uma proposta multidimensional não totalitária e não doutrinária, que proporciona conexão flexível entre incerteza física e indecibilidade teórica (Morin, 2005).

Complementarmente, os princípios da termodinâmica não fazem apenas papel de condições de contorno complementares ou indesejáveis, passam a fazer parte integrante da concepção dos projetos e obras representando importante abertura epistêmica (Morin, 2005).

\section{Auto-organização e não linearidade}

Sinais aleatórios espúrios, chamados genericamente de ruídos, parecem ser uma grande dificuldade para a boa operação de sistemas eletrônicos, em comunicações e instrumentação. A concepção de um projeto nessas áreas começa pela especificação da relação sinal-ruído, i.e., de quantas vezes o sinal é mais intenso do que o ruído.

Daí decorre o teorema fundamental da teoria da informação: caso a relação sinal-ruído de uma fonte de dados seja maior ou igual à capacidade do canal, é sempre possível codificar os dados e transmiti-los para um receptor, com pequena e arbitrária taxa de erros (Shannon; Weaver, 1963).

Além do conhecimento advindo da teoria da informação, os engenheiros de eletrônica e comunicações serviram-se amplamente da teoria de processos estocástico, do eletromagnetismo e da teoria dos circuitos para desenvolverem dispositivos de modulação e demodulação, responsáveis pela prontidão e ubiquidade dos acessos à internet.

Originalmente, esses avanços foram obtidos por projetos e dispositivos lineares, isto é, aqueles que satisfazem o princípio da superposição: o efeito da soma é a soma dos efeitos. Essa é uma hipótese que, quando satisfeita, proporciona facilidade de projeto e precisão de operação.

Entretanto, os componentes eletrônicos apresentam não linearidades e superposição de efeitos nem sempre satisfeita, fato que pode dificultar os projetos, mas incrementá-los, se bem utilizado.

Em meados dos anos 1980, houve uma grande movimentação no mundo da física e da engenharia mecânica com origem na facilidade computacional de simular sistemas dinâmicos descritos por equações diferenciais não lineares (Monteiro, 2006), produzindo o chamado caos determinístico.

Entende-se por caos determinístico o comportamento aleatório de um sistema dinâmico descrito por equações não lineares deterministas, associado à emergência de comportamentos sensíveis às condições iniciais. Está então criada a dicotomia, sempre própria da complexidade (Morin, 2005): o imprevisível dentro do previsível. 
Alguns circuitos elétricos apresentando esse fenômeno foram desenvolvidos e os campos da modulação e da criptografia ficaram enriquecidos com essas novas possibilidades.

O caos determinístico e sua emergência fazem parte integrante da Engenharia da Complexidade em suas diversas atividades de concepção e projeto, aprimorando a acuidade dos modelos das interações e, na implantação e operação, permitindo a visualização de uma variedade maior de cenários.

Outro fator a ser considerado no contexto da Engenharia da Complexidade é o da auto-organização do sistema constituído pela obra e seu entorno físico, biológico e humano. A interação física, por mais complicada que seja, tem metodologias relativamente bem desenvolvidas para serem estudadas e contextualizadas.

As interações biológicas podem trazer maiores e mais inesperadas surpresas. Alterações ambientais produzidas por uma ação de Engenharia podem implicar degradações de paisagens e propagação de doenças.

O fator mais relevante a ser incluído é, entretanto, o antropológico. Obras de engenharia são trabalhos humanos que devem visar a melhoria da vida no planeta, sob os mais variados aspectos.

Não se pode esquecer que seres humanos são dotados de consciência e discernimento, o que pode influenciar de maneira direta decisões de concepção, projeto, implantação e operação de um sistema e, principalmente, contextualizá-los às condições humanas de cada população.

De nada adianta construir estradas modernas em locais em que as populações são tão carentes que sequer gozam de mobilidade. Da mesma forma, com a necessidade premente de água e energia para manutenção da vida, não faz sentido coibir o desenvolvimento de fontes alternativas e de mecanismos de despoluição de mananciais.

Interesses de grandes grupos econômicos podem trabalhar contra a erradicação da fome no planeta e fanatismos bélicos e religiosos podem fomentar desenvolvimento de máquinas de destruição.

O balanço cultural, social e econômico é o ponto central da Engenharia da Complexidade que, além de transdisciplinar, deve ser uma ferramenta de entendimento, paz e qualidade de vida para todos.

\section{Sistema de Sistemas e Incompletude}

Uma das discussões prediletas dos vendedores de novos produtos e dos entusiastas das novidades tem sido sobre as cidades inteligentes e sobre a chamada internet das coisas.

Fabricantes tradicionais de hardware e software promovem simpósios, oferecem soluções gratuitas para demonstração, financiam desenvolvimento e publicações, visando liderar um mercado aparentemente muito promissor.

Há soluções para a segurança de logradouros e residências, para monitoração de acidentes, enchentes e multidões. Há até ministro encantado com a 
possibilidade de ligar o liquidificador da casa remotamente. O difícil será tomar o suco remotamente, uma vez que o teletransporte das pessoas e das coisas ainda é ficção cinematográfica.

Esse é o jeito tradicional de olhar os problemas de engenharia, pensando nos modelos físicos. Cada sistema como sendo único, fechado e voltado para uma finalidade exclusiva.

O pensamento complexo aplicado às cidades inteligentes e à internet das coisas começaria pelo pensamento antropológico, integrando o biológico e o físico.

Uma cidade inteligente começa pela cultura e pelo conforto e qualidade de vida da população que a ocupa sendo, portanto, um sistema de sistemas, definido e concebido caso a caso.

Pensando no território brasileiro, não há como achar que tornar São Paulo inteligente seja colocar semáforos sincronizados nos grandes corredores de tráfego ou monitorar as áreas de enchente. Há muitos problemas anteriores: déficit habitacional, pobreza, concentração de populações em áreas de infraestrutura precária, crianças fora das escolas, criminalidade e tantos outros.

A Engenharia da Complexidade contém em sua proposta a integração de todos esses fatores, formando os chamados sistemas de sistemas. Essa forma de pensamento melhora a eficácia das soluções, mas como toda solução, é incompleta, pois jamais poderemos ter um saber total: "A totalidade é a não verdade" (Morin, 2005).

Trata-se de enfrentar um emaranhado de inter-relações e realimentações, a incerteza e a contradição usando as ferramentas conceituais já desenvolvidas e as novas, emergentes de diferentes e inovadoras linhas de raciocínio.

Conciliar unidade e diversidade, continuidade e rupturas é tarefa do pensamento complexo que, semelhante aos sistemas lógicos, é incompleto.

\section{Conclusão}

Uma engenharia que leva em conta o físico sem "fisicismo", o biológico sem "biologismo" e o antropológico sem "antropologismo" é a proposta da Engenharia da Complexidade, indo além do complicado e passando pelo consciente, talvez diminuindo as desigualdades, mantendo o respeito à identidade.

Nota

1 Palestra proferida no Instituto de Estudos Avançados da USP em 22 de setembro de 2017.

\section{Referências}

BERTALANFFY, L. Von. General System Theory: foundations, development, applications. New Yoir: George Braziller Inc., 1968. 
KONDEPUDI, D.; PRIGOGINE, I. Modern Thermodynamics: From Heat Engines to Dissipative Structures. 2.ed. Susex UK: John Wiley and Sons Ltda., 2015.

MONTEIRO, L. H. A. Sistemas dinâmicos. 2.ed. São Paulo: Livraria da Física, 2006.

MORIN, E. Introdução ao pensamento complexo. 5.ed. Porto Alegre: Sulina, 2005. PIQUEIRA, J. R. C. A mathematical view of Biological complexity. Communications in Nonlinear Science and Numerical Simulation, v.14, n.6, p.2581-6, 2009.

SHANNON, C. E.; WEAVER W. The Mathematical Theory of Communication. Urbana; Chicago - USA: Illini Books Edition, 1963.

RESUMO - Este artigo apresenta uma proposta de abordagem de engenharia, a Engenharia da Complexidade, considerando os pressupostos do pensamento complexo apresentado por Edgar Morin. Os fundamentos principais desse enfoque: projeto de sistemas abertos, emergência, inclusão da aleatoriedade e incompletude Gödeliana são contextualizados em exemplos reais de problemas construtivos.

Palavras-Chave: Complexidade, Caos, Dinâmica, Incompletude, Não linearidade, Sistema aberto.

ABSTRACT - This paper proposes an approach to Complexity Engineering, that takes into account the complex thinking framework proposed by Edgar Morin. The main foundations of this approach are open systems design, emergence, and the inclusion of Gôdel's randomness and incompleteness, which are contextualized in real-life constructive problems.

KErWORDs: Complexity, Chaos, Dynamics, Incompleteness, Non-linearity, Open system.

José Roberto Castilho Piqueira é engenheiro eletricista e mestre em engenharia elétrica pela Escola de Engenharia de São Carlos da USP, doutor e livre-docente em engenharia de sistemas pela Escola Politécnica da USP. É professor titular da Escola Politécnica da USP. @-piqueira@lac.usp.br

Recebido em 20.9.2017 e aceito em 25.10.2017.

I Escola Politécnica, Universidade de São Paulo, São Paulo, São Paulo, Brasil. 